\title{
BMJ Open Insulin analogues use in pregnancy among women with pregestational diabetes mellitus and risk of congenital anomaly: a retrospective population- based cohort study
}

\author{
Hao Wang, ${ }^{1}$ Ewa Wender-Ozegowska, ${ }^{2}$ Ester Garne, ${ }^{3}$ Margery Morgan, ${ }^{4}$ \\ Maria Loane, ${ }^{5}$ Joan K Morris, ${ }^{6}$ Marian K Bakker, ${ }^{7}$ Miriam Gatt, ${ }^{8}$ Hermien de Walle, ${ }^{7}$ \\ Susan Jordan, ${ }^{9}$ Anna Materna-Kiryluk, ${ }^{10}$ Vera Nelen, ${ }^{11}$ Guy Thys, ${ }^{11}$ Awi Wiesel, ${ }^{12}$ \\ Helen Dolk, ${ }^{13}$ Lolkje T W de Jong-van den Berg ${ }^{1}$
}

To cite: Wang $\mathrm{H}$, WenderOzegowska E, Garne E, et al. Insulin analogues use in pregnancy among women with pregestational diabetes mellitus and risk of congenital anomaly: a retrospective populationbased cohort study. BMJ Open 2018;8:e014972. doi:10.1136/ bmjopen-2016-014972

\section{- Prepublication history and} additional material for this paper are available online. To view these files, please visit the journal online (http://dx.doi. org/10.1136/bmjopen-2016014972).

Received 6 December 2016 Revised 8 January 2018 Accepted 9 January 2018

\section{Check for updates}

For numbered affiliations see end of article.

Correspondence to

Dr Hao Wang; hao.wang@rug.nl

\section{ABSTRACT}

Objectives To evaluate the risk of major congenital anomaly associated with first-trimester exposure to insulin analogues compared with human insulin in offspring of women with pregestational diabetes.

Design and setting A population-based cohort of women with pregestational diabetes $(n=1661)$ who delivered between 1996 and 2012 was established retrospectively from seven European regions covered bythe European Surveillance of Congenital Anomalies (EUROCAT) congenital anomaly registries.

Primary outcome measures The risk of nonchromosomal major congenital anomaly in live births, fetal deaths and terminations for a fetal anomaly exposed to insulin analogues in the first trimester of pregnancy was compared with the risk in those exposed to human insulin only.

Results During the first trimester, 870 fetuses (52.4\%) were exposed to human insulin only, 397 fetuses (23.9\%) to insulin analogues only and 394 fetuses $(23.7 \%)$ to both human insulin and insulin analogues. The risk of major congenital anomaly in fetuses exposed to insulin analogues only was lower than those exposed to human insulin only; the relative risk adjusted for glycaemic control and region was 0.56 (95\% $\mathrm{Cl} 0.29$ to 1.06). The significantly lower risk related to exposure of insulin analogues only was observed in congenital heart defects: adjusted relative risk $0.14(95 \% \mathrm{Cl} 0.03$ to 0.62$)$.

Conclusions In this retrospective population-based cohort study across Europe, first-trimester exposure to insulin analogues did not increase the risk of major congenital anomaly compared with exposure to human insulin. A possible lower risk of congenital heart defects among fetuses exposed to insulin analogues only deserves further investigation.

\section{INTRODUCTION}

Women with pregestational diabetes mellitus (DM) (type 1 or type 2) have a higher risk of serious adverse pregnancy outcomes,

\section{Strengths and limitations of this study}

- A large retrospective population-based cohort of diabetic pregnancies from multiple centres that represent geographically distinct areas where patterns of diabetic treatment are different.

- The valid information on congenital anomaly was obtained by linkage to the EUROCAT database and by reclassification the cases with written text descriptions of a congenital anomaly based on EUROCAT subgroup definition.

- The data sources which were based on medical records and healthcare databases had incomplete data on haemoglobin $\mathrm{A} 1 \mathrm{c}(\mathrm{HbA1c})$ and pregnancy planning, but the association of congenital anomalies and insulin analogues was examined only among women who had had a HbA1c in the first trimester.

- The database does not contain information on lifestyle factors (eg, smoking, obesity, alcohol), preconception care (eg, screening and treatment of complications of diabetes, folic acid supplementation) which are also known to lower the risk of congenital anomaly.

including stillbirth, major congenital anomalies, and neonatal morbidity and mortality ${ }^{1-5}$ compared with women without diabetes. Isolated congenital heart defects account for one-third of all congenital anomalies in pregnancies with diabetes and a quarter in pregnancies without diabetes. ${ }^{6}$ Although the mechanisms underlying the associations of DM with congenital anomalies are not completely understood, there is evidence for a positive association between hyperglycaemia during embryogenesis and the risk for congenital anomalies. ${ }^{78}$ Preconception care focusing on glycaemic control can improve pregnancy outcome and reduce 
the frequency of congenital anomalies in women with DM. ${ }^{9}$

Clinical and experimental studies report that insulin analogues result in improved glycaemic control, more stable glycaemia, less glucose spikes, fewer hypoglycaemic episodes and improved patient satisfaction compared with the use of human insulin, ${ }^{10-12}$ which might have benefits for pregnant women. However, studies on exposure to insulin analogues during pregnancy are small and underpowered to evaluate the risk of specific major congenital anomalies. ${ }^{13}$ We conducted a study using a cohort of pregnancies with diabetes across Europe to evaluate the risk of major congenital anomalies associated with insulin analogue use in the first trimester of pregnancy compared with the use of human insulin.

\section{METHODS}

\section{Study population}

A multicentre, retrospective cohort study was performed in seven regions in Europe, belonging to the EUROCAT network of population-based congenital anomalies registries, all obliged to value the same definitions, standards and procedures. Inclusion criteria were women with pregestational diabetes who had been referred to the hospitals in the region of study centre and delivered between 1996 and 2012. The study included live births, fetal deaths (spontaneous abortion, stillbirths) and terminations for a fetal anomaly. Selection of study centres that captured pregnant women with DM for this study was on the basis of contacts within the EUROCAT network. The population of the study centre had to be covered by the EUROCAT network in order to evaluate the pregnancy outcome in terms of congenital anomaly. Each centre should include information on the key variables for evaluating insulin analogues use in the first trimester. Information on maternal drug exposure and other confounders was obtained from medical records. A total of 1877 fetuses of women with pregestational diabetes were enrolled in the study. We excluded 160 fetuses exposed to oral glucose-lowering medications in the first trimester and 56 fetuses with unspecified maternal treatment of diabetes. The final cohort for the study included 1661 fetuses from 1634 pregnancies.

\section{Database of cohort with diabetes}

Data on maternal demographics, type of diabetes, treatment, that is, the name of the medication or complete seven-digit Anatomical Therapeutic Chemical classification code, including the dispensing date and number of days of supply, duration of diabetes before conception, planned pregnancy, haemoglobin A1c (HbAlc) level and neonatal outcomes were collected from local medical records.

\section{EUROCAT database}

Details of the EUROCAT central database have been described previously. ${ }^{14}$ Congenital anomalies among live births, fetal deaths and terminations for a fetal anomaly are standardly recorded according to EUROCAT Guide $1.3 .{ }^{15}$ One syndrome and up to eight malformations are coded by International Classification of Diseases, Ninth Revision (ICD9) or 10th Revision (ICD10) codes. Minor anomalies, according to the EUROCAT classification system, are excluded. The follow-up period for inclusion of congenital anomaly in the EUROCAT varies among study regions: up to 1 week after birth in Mainz, up to 1 year after birth in Antwerp, Malta and Wales, up to 2 years after birth in Poznan, up to 5 years after birth in Funen and up to 16 years after birth in Northern Netherlands.

\section{Exposure definition}

The relevant exposure period was defined from the date of the last menstrual period to week 13 of pregnancy (first trimester). All fetuses were classified according to first-trimester maternal treatment of diabetes. The following three groups were included in the analysis: (1) fetuses exposed to human insulin only, (2) fetuses exposed to insulin analogue only and (3) fetuses exposed to both human insulin and insulin analogue. The reference group was fetuses exposed to human insulin only in the first trimester.

\section{Outcome definitions}

The primary outcome of interest was defined as the diagnosis of a major congenital anomaly in the infant/fetus, while the secondary outcome was a diagnosis of congenital heart defects. Written descriptions of congenital anomalies based on medical records for live births, fetal deaths and terminations for a fetal anomaly at any gestational age were recorded in the database of cohort with diabetes. A two-stage process was used to identify and confirm fetuses with a major congenital anomalies. First, major congenital anomalies were identified by linking the database of cohort with diabetes to the EUROCAT central database. Second, unlinked cases with a written description of congenital anomalies were reviewed by a paediatrician (EG), blind to exposure status, to classify them into major versus minor congenital anomalies. All major congenital anomalies were grouped according to the EUROCAT classification system. ${ }^{15}$ Fetuses with minor anomalies according to EUROCAT criteria were counted as not having a congenital anomaly diagnosis. Chromosomal anomalies $(n=5)$ were excluded from major congenital anomalies and congenital heart defects in the analysis of risk estimation and EUROCAT organ subgroup categorisation.

Preterm birth was defined as delivery before 37 weeks of gestation. We determined the percentile for birth weight for each neonate based on the gestational age using Dutch sex-specific standards. ${ }^{16}$ Large for gestational age (LGA) was defined as those above the 90th percentile weight by gestational age and sex. An adverse pregnancy outcome was defined as a major congenital anomaly or a fetal death, which included spontaneous abortion (gestational age $<20$ weeks) and stillbirth (gestational age $\geq 20$ weeks). 


\section{Statistical analyses}

We compared the distributions of maternal and neonatal characteristics among the three exposure groups. One-way analysis of variance was used to compare the mean differences in maternal age at delivery, gestational age and birth weight for live births only between exposure groups, and the Scheffe multiple comparison test was used for comparison with the reference group (human insulin only). Multinomial logistic regression was used to identify the differences in categorical variables between exposure groups. Associations between congenital anomalies/congenital heart defects and treatment of diabetes were estimated by calculating both crude and adjusted ORs and their 95\% CIs using logistic regression models. ORs were adjusted for study centre (using a random-effect model) and HbA1c levels in the first trimester. HbA1c levels were collected from 3 months before pregnancy until delivery and a mean value was calculated for each trimester. The mean HbA1c level in the first trimester was classified into four categories: mean HbA1c $\leq 43 \mathrm{mmol} /$ mol $(\leq 6.1 \%)$, mean HbAlc $44-53 \mathrm{mmol} / \mathrm{mol}(6.2 \%-$ $7.0 \%)$, mean HbAlc $54-67 \mathrm{mmol} / \mathrm{mol}(7.1 \%-8.3 \%)$ and mean $\mathrm{HbA} 1 \mathrm{c}>67 \mathrm{mmol} / \mathrm{mol}(>8.3 \%)$ and unknown. Missing HbA1c levels in the first trimester $(n=614)$ were excluded from the main analysis of risk estimation of major congenital anomalies/congenitalheart defects, because the first-trimester level of HbAlc is essential when considering congenital abnormalities. A sensitivity analysis was conducted by including missing HbAlc as a separate group in the multivariate logistic model (online supplementary table). Analyses were performed using STATA V.13.

\section{RESULTS}

During the first trimester, $870(52.4 \%)$ fetuses were exposed to human insulin only, 397 (23.9\%) fetuses to insulin analogues only, 394 (23.7\%) fetuses to both human insulin and insulin analogues. Of 397 fetuses exposed to insulin analogues only, 277 were exposed to short-acting insulin analogues only: 169 to insulin lispro, 106 to insulin aspart and 1 to insulin glulisine. Of 120 fetuses exposed to short-acting insulin analogues with long-acting insulin analogues, 93 were exposed to insulin glargine and 27 exposed to insulin detemir. The proportion of insulin analogues only exposed fetuses increased from $3.2 \%$ in $1996-2002$ to $20.8 \%$ in $2003-2007$, and to $39.3 \%$ in the period $2008-2012$. We found regional differences in the proportion of exposure to insulin analogues only in the first trimester ranging from $3.8 \%$ in Malta to $59.6 \%$ in Wales (table 1 ).

Compared with fetuses exposed to human insulin only in the first trimester, fetuses exposed to insulin analogues only were more common among women who planned their pregnancies $(49.4 \%$ vs $23.9 \%, \mathrm{P}<0.0001)$, with type 1 diabetes $(95.5 \%$ vs $90.9 \%, \mathrm{P}<0.004)$ and who had a longer duration of diabetes $(64.2 \%$ vs $46.6 \%$, $\mathrm{P}<0.0001)$. Overall, the mean HbA1c value in the first trimester was $55.5 \mathrm{mmol} / \mathrm{mol}$ (7.2\%) (SD 16.1), Fetuses exposed to insulin analogue only in the first trimester were more likely to be in mean HbA1c $44-53 \mathrm{mmol} / \mathrm{mol}$ (6.2\%-7.0\%) group compared with those exposed to human insulin only $(29.5 \%$ vs $13.8 \%, \mathrm{P}<0.001)$ (table 2$)$. Neonatal outcomes in terms of gender, LGA, death in the first week were similar among all groups. The proportion of spontaneous abortion was $1.5 \% \quad(n=6)$ among fetuses exposed to insulin analogues only, and $1.3 \%$ $(n=5)$ among fetuses exposed to both insulin analogues and human insulin. These rates were significantly higher than fetuses exposed to human insulin only $0.1 \%(n=1)$ (table 2). Major congenital anomalies were observed in $70(8.0 \%)$ fetuses with human insulin only exposure, 15 (3.8\%) fetuses with insulin analogue only exposure and 19 $(4.8 \%)$ fetuses with human insulin and insulin analogue exposure. Fetuses from Northern Netherlands had the lowest rate of congenital anomaly overall $(2.1 \%, 95 \%$ CI $0.9 \%$ to $4.7 \%$ ). The highest rate of congenital anomaly was seen in Antwerp (12.3\%, 95\% CI 7.3\% to 19.8\%).

A total of 1047 fetuses whose mother had a first-trimester HbA1c were included in the analysis of the risk estimation of congenital anomalies/congenitalheart defects. Compared with fetuses exposed to human insulin only, those exposed to insulin analogues only had a lower

Table 1 Diabetic treatment in the first trimester by centre

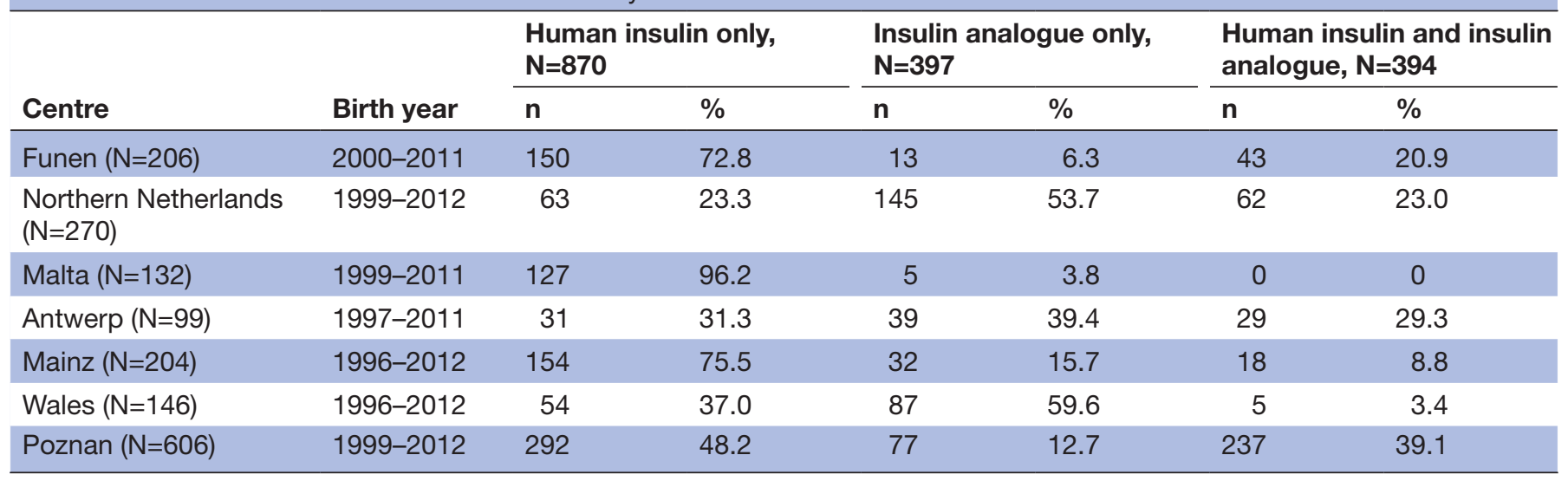


Table 2 Maternal and infant characteristics by treatment of diabetes in the first trimester

\begin{tabular}{|c|c|c|c|}
\hline & $\begin{array}{l}\text { Human insulin only, } \\
\mathrm{n}(\%)\end{array}$ & $\begin{array}{l}\text { Insulin analogue only, } \\
\text { n (\%) }\end{array}$ & $\begin{array}{l}\text { Human insulin and } \\
\text { insulin analogue, } \\
\text { n (\%) }\end{array}$ \\
\hline N & 870 & 397 & 394 \\
\hline \multicolumn{4}{|l|}{ Maternal characteristics } \\
\hline Maternal age, mean (SD) & $29.3 \pm 5.2$ & $29.8 \pm 5.1$ & $29.1 \pm 5.4$ \\
\hline Maternal age, $>35$ years & $150(17.2)$ & 67 (16.9) & $67(17.0)$ \\
\hline Multiparous & $515(59.2)$ & $216(54.4)$ & $211(53.6)$ \\
\hline Planned pregnancy & $208(23.9)$ & $196(49.4)^{\star}$ & 139 (35.3) \\
\hline Type 1 diabetes & 791 (90.9) & $379(95.5)$ & $359(91.1)$ \\
\hline Duration of diabetes, $>10$ years & $405(46.6)$ & $255(64.2)^{*}$ & $188(47.7)$ \\
\hline Chronic hypertension & $42(4.8)$ & $25(6.3)$ & $15(3.8)$ \\
\hline \multicolumn{4}{|l|}{$\mathrm{HbA1c}$ first trimester } \\
\hline$\leq 43 \mathrm{mmol} / \mathrm{mol}(\leq 6.1 \%)$ & $109(12.5)$ & $54(13.6)$ & $66(16.8)$ \\
\hline $44-53 \mathrm{mmol} / \mathrm{mol}(6.2 \%-7.0 \%)$ & $120(13.8)$ & $117(29.5)^{\star}$ & $66(16.8)$ \\
\hline $54-67 \mathrm{mmol} / \mathrm{mol}(7.1 \%-8.3 \%)$ & $134(15.4)$ & $86(21.7)$ & $94(23.9)$ \\
\hline$>67 \mathrm{mmol} / \mathrm{mol}(>8.3 \%)$ & $100(11.8)$ & $54(13.6)$ & 47 (11.9) \\
\hline Unknown & 407 (46.8) & $86(21.7)$ & $121(30.7)$ \\
\hline \multicolumn{4}{|l|}{ Infant characteristics } \\
\hline \multicolumn{4}{|l|}{ Birth year } \\
\hline$\leq 2002$ & $363(41.7)$ & $13(3.3)$ & $25(6.4)$ \\
\hline 2003-2007 & $357(41.0)$ & $126(31.7)^{*}$ & $121(30.7)^{\star}$ \\
\hline 2008-2012 & $150(17.3)$ & $258(65.0)^{*}$ & $248(62.9)^{\star}$ \\
\hline \multicolumn{4}{|l|}{ Fetal outcome } \\
\hline Live birth & 855 (98.3) & $380(95.7)$ & $380(96.4)$ \\
\hline Stillbirth & $11(1.3)$ & $10(2.5)$ & $7(1.8)$ \\
\hline Spontaneous abortion & $1(0.1)$ & $6(1.5)^{\star}$ & $5(1.3)^{\star}$ \\
\hline Termination & $3(0.3)$ & $1(0.3)$ & $2(0.5)$ \\
\hline Male sex & $456(52.4)$ & $200(50.4)$ & $208(52.8)$ \\
\hline Preterm delivery $\ddagger,<37$ weeks & $249(29.2)$ & $122(32.7)$ & $80(21.1)^{*}$ \\
\hline Large for gestation $\ddagger$ & $413(48.7)$ & 197 (53.4) & $184(48.6)$ \\
\hline Death in the first week $\neq$ & $6(0.8)$ & $1(0.3)$ & 0 \\
\hline
\end{tabular}

The range of gestational age is $6-42$ weeks.

${ }^{*} \mathrm{P}<0.05$.

†Reference group for comparison was fetuses exposed to human insulin only in the first trimester.

$\ddagger$ Among live birth.

$\mathrm{HbA1c}$, haemoglobin A1c.

risk of major congenital anomaly (OR $0.54 ; 95 \%$ CI 0.29 to 1.01 ), but not statistically significant. The risk of major congenital anomaly was significantly lower among those exposed to both human insulin and insulin analogues (OR $0.43 ; 95 \%$ CI 0.21 to 0.89 ). Mean HbAlc level in the first trimester was significantly associated with major congenital anomaly, with OR of 2.87 (95\% CI 1.28 to 6.42) for the HbA1c level above $67 \mathrm{mmol} / \mathrm{mol}(8.3 \%)$. Adjusting for the mean HbAlc in the first trimester and region did not change the risk estimates (table 3 ). The OR of congenital heart defects adjusted for region and HbAlc was 0.14 (95\% CI 0.03 to 0.62 ) among fetuses with exposure to insulin analogue only, and $0.47(95 \%$ CI 0.19 to 1.19 ) among those with exposure to both human insulin and insulin analogue, compared with the reference group (table 3). In the analysis of adverse outcomes (major congenital anomaly or fetal death), the point estimates did not show increased risks associated with exposure to insulin analogues (either alone or with human insulin), with an adjusted OR of 0.76 (95\% CI 0.44 to 1.33 ) for those exposed to insulin analogue only (table 3 ). In the sensitivity analysis, missing HbAlc levels in the first trimester $(n=614)$ were included as a separate group in the multivariate model (online supplementary 
Table 3 Relative risk of non-chromosomal congenital anomalies by treatment of diabetes in the first trimester

\begin{tabular}{|c|c|c|c|}
\hline & $\begin{array}{l}\text { Human insulin only, } \\
\mathrm{N}=463\end{array}$ & $\begin{array}{l}\text { Insulin analogue only, } \\
\mathrm{N}=311\end{array}$ & $\begin{array}{l}\text { Human insulin and } \\
\text { insulin analogue, } N=273\end{array}$ \\
\hline \multicolumn{4}{|l|}{ Major congenital anomaly } \\
\hline n (\%) & $37(8.0)$ & $14(4.5)$ & $10(3.7)$ \\
\hline Crude OR (95\% Cl) & Reference & $0.54(0.29$ to 1.01$)$ & $0.43(0.21$ to 0.89$)$ \\
\hline Adjusted OR $(95 \% \mathrm{Cl})^{\star}$ & Reference & 0.56 (0.29 to 1.06$)$ & 0.44 (0.22 to 0.91$)$ \\
\hline \multicolumn{4}{|l|}{ Congenital heart defects } \\
\hline n (\%) & $21(4.5)$ & $2(0.6)$ & $6(2.2)$ \\
\hline Crude OR (95\% CI) & Reference & 0.14 (0.03 to 0.58$)$ & $0.46(0.18$ to 1.15$)$ \\
\hline Adjusted OR $(95 \% \mathrm{Cl})^{\star}$ & Reference & 0.14 (0.03 to 0.62$)$ & 0.47 (0.19 to 1.19$)$ \\
\hline \multicolumn{4}{|l|}{ Adverse outcomes $†$} \\
\hline$n(\%)$ & $42(9.1)$ & $21(6.8)$ & $19(7.0)$ \\
\hline Crude OR (95\% CI) & Reference & 0.72 (0.42 to 1.24$)$ & 0.74 (0.42 to 1.31$)$ \\
\hline Adjusted OR $(95 \% \mathrm{Cl})^{\star}$ & Reference & 0.76 (0.44 to 1.33$)$ & 0.77 (0.44 to 1.36$)$ \\
\hline
\end{tabular}

*Adjusted for centre as a random effect and adjusted for $\mathrm{HbA1c}$ value in the first trimester.

†Including major congenital anomaly or fetal deaths.

$\mathrm{HbA1c}$, haemoglobin A1c.

table 1). The estimated ORs of major congenital anomaly overall or congenital heart defects with insulin analogue use were similar.

Planned pregnancy was associated with a lower risk of major congenital anomalies (OR $0.73,95 \%$ CI 0.37 to $1.46)$ and for congenital heart defects (OR $0.28,95 \% \mathrm{CI}$ 0.20 to 1.58$)$. Adjusting for other potential confounders (maternal age, planned pregnancy, diabetes type and year of delivery) did not significantly affect the estimated ORs of major congenital anomalies overall or congenital heart defects with insulin analogues use (data not shown).

Out of 311 fetuses exposed to insulin analogues only, 217 $(69.8 \%)$ were exposed to short-acting insulin analogues only and $94(19.2 \%)$ were exposed to a combination of long-acting analogues with short-acting insulin analogues (table 4). When analyses were restricted to fetuses exposed to insulin analogues only, the significantly lower risk of major congenital anomalies/congenital heart defects was

Table 4 ORs of non-chromosomal congenital anomalies by type of insulin analogues among fetuses exposed to insulin analogues only in the first trimester

\begin{tabular}{|c|c|c|c|}
\hline \multirow[b]{3}{*}{$\mathbf{N}$} & \multirow[b]{2}{*}{ Human insulin only } & \multicolumn{2}{|l|}{ Insulin analogues only } \\
\hline & & $\begin{array}{l}\text { Short-acting analogues } \\
\text { only }\end{array}$ & $\begin{array}{l}\text { Short-acting analogues and } \\
\text { long-acting analogues }\end{array}$ \\
\hline & 463 & 217 & 94 \\
\hline \multicolumn{4}{|l|}{ Major congenital anomaly } \\
\hline n (\%) & $37(8.0)$ & $9(4.2)$ & $5(5.3)$ \\
\hline Crude OR $(95 \% \mathrm{Cl})$ & Reference & 0.49 (0.23 to 1.04$)$ & 0.64 (0.24 to 1.68$)$ \\
\hline Adjusted OR $(95 \% \mathrm{Cl})^{*}$ & Reference & 0.57 (0.26 to 1.21$)$ & 0.54 (0.20 to 1.43$)$ \\
\hline \multicolumn{4}{|l|}{ Congenital heart defects } \\
\hline n (\%) & $21(4.5)$ & $1(0.5)$ & $1(1.1)$ \\
\hline Crude OR $(95 \% \mathrm{Cl})$ & Reference & 0.10 (0.01 to 0.72$)$ & $0.23(0.03$ to 1.70$)$ \\
\hline Adjusted OR $(95 \% \mathrm{Cl})^{*}$ & Reference & 0.12 (0.02 to 0.92$)$ & $0.18(0.02$ to 1.35$)$ \\
\hline \multicolumn{4}{|l|}{ Adverse outcomes $†$} \\
\hline n (\%) & $42(9.1)$ & $15(6.9)$ & $6(6.4)$ \\
\hline Crude OR (95\% Cl) & Reference & 0.74 (0.40 to 1.36$)$ & 0.68 (0.28 to 1.64$)$ \\
\hline Adjusted OR $(95 \% \mathrm{Cl})^{\star}$ & Reference & 0.94 (0.45 to 1.98$)$ & $0.53(0.21$ to 1.36$)$ \\
\hline
\end{tabular}

${ }^{*}$ Adjusted for centre as a random effect and adjusted for $\mathrm{HbA1c}$ value in the first trimester.

tIncluding major congenital anomaly or fetal deaths.

$\mathrm{HbA1c}$, haemoglobin A1c. 
Table 5 Prevalence* of non-chromosomal congenital anomaly subgroups by treatment of diabetes in the first trimester

\begin{tabular}{|c|c|c|c|}
\hline & $\begin{array}{l}\text { Human insulin only } \\
\mathrm{N}=870\end{array}$ & $\begin{array}{l}\text { Insulin analogues only } \\
\mathrm{N}=397\end{array}$ & $\begin{array}{l}\text { Human insulin and } \\
\text { insulin analogue } \\
\mathrm{N}=394\end{array}$ \\
\hline EUROCAT subgroups & $\mathrm{n}($ per 1000) & $\mathrm{n}$ (per 1000) & $\mathrm{n}($ per 1000) \\
\hline Nervous system & $11(12.6)$ & $2(5.0)$ & $2(5.1)$ \\
\hline Ear, face and neck & $1(1.1)$ & 0 & 0 \\
\hline Congenital heart defects & $35(40.2)$ & $3(7.6)$ & $14(35.5)$ \\
\hline Severe congenital heart defects & $2(2.3)$ & 0 & $4(10.2)$ \\
\hline Transposition of great vessels & 0 & 0 & $2(5.1)$ \\
\hline Single ventricle & $1(1.1)$ & 0 & 0 \\
\hline Ventricular septal defect & $20(23.0)$ & $1(2.5)$ & $9(22.8)$ \\
\hline Atrial septal defect & $12(13.8)$ & $2(5.0)$ & $2(5.1)$ \\
\hline Tetralogy of Fallot & 0 & 0 & $1(2.5)$ \\
\hline $\begin{array}{l}\text { PDA as only congenital heart defects in term } \\
\text { infants (GA }+37 \text { weeks) }\end{array}$ & $1(1.1)$ & 0 & $1(2.5)$ \\
\hline Respiratory & $1(1.1)$ & $1(2.5)$ & $1(2.5)$ \\
\hline Orofacial clefts & $1(1.1)$ & $2(5.0)$ & 0 \\
\hline Digestive system & $5(5.7)$ & 0 & $2(5.1)$ \\
\hline Urinary & $10(11.5)$ & $3(7.6)$ & $1(2.5)$ \\
\hline Genital & $3(3.4)$ & $2(5.0)$ & $2(5.1)$ \\
\hline Limb & $9(10.3)$ & $4(10.1)$ & $1(2.5)$ \\
\hline Other anomalies/syndromes & $4 \dagger(4.6)$ & 0 & $1 \ddagger(2.5)$ \\
\hline
\end{tabular}

${ }^{*}$ One fetus can be counted in more than one subgroup if it has multiple malformations, but only once in total. †Including craniosynostosis $(n=2)$, teratogenic syndromes with malformations $(n=1)$, genetic syndromes+microdeletions $(n=1)$. $\ddagger$ Situs inversus $(\mathrm{n}=1)$.

GA, gestational age; PDA, patent ductus arteriosus.

seen in fetuses exposed to short-acting insulin analogue only (OR $0.12,95 \%$ CI 0.02 to 0.92 ), although the point estimates were similar between exposure to short-acting insulin analogue only and short-acting and long-acting insulin analogues (table 4).

Table 5 describes the specific congenital anomalies diagnosed in all fetuses $(n=1661)$. Congenital heart defects were the most frequent except in those exposed to insulin analogues only. Of the three congenital heart defects cases among insulin analogues only group, two were atrial septal defect (ASD) and one ventricular septal defect (VSD). Of the 35 fetuses with congenital heart defects exposed to human insulin only, two had severe congenital heart defects and the remaining 33 cases had septal defects or persistent ductus. There were no cases with caudal regression sequence.

\section{DISCUSSIONS}

In this retrospective population-based cohort study, we found no increase in the risk of congenital anomalies in fetuses exposed to insulin analogues in the first trimester compared with those exposed to human insulin. Furthermore, a significantly lower risk of congenital heart defects was observed with exposure to insulin analogues.
In this cohort of pregnancies with diabetes, the rate of major congenital anomalies was $7.0 \%$ and about half of all major congenital anomalies were congenital heart defects. These rates are comparable with previous reports which found that the risk of congenital anomalies in the offspring of women with diabetes was between $4.6 \%$ and $9.7 \%,{ }^{2-417}$ a twofold to fivefold increase in risk compared with the general population in the study region. ${ }^{18}$ Our study confirms that unplanned pregnancy ${ }^{2}$ and elevated HbAlc levels in the first trimester are associated with a higher rate of congenital anomalies. ${ }^{19} 20$

In Europe, insulin analogues have been increasingly used during pregnancy in the last decade, ${ }^{21}$ and so, it is important to assess their safety. Studies have consistently showed no increased risk of congenital anomalies overall with the use of insulin analogues in pregnancy compared with the use of human insulin. ${ }^{22-25}$ Among a number of retrospective and observational studies on insulin lispro, the largest was a retrospective multinational study of 533 pregnancies with pregestational diabetes, ${ }^{22}$ which reported a rate of major congenital anomalies of $5.4 \%$ $(\mathrm{n}=27,95 \%$ CI $3.5 \%$ to $7.4 \%)$. An open-label randomised controlled trial found a $4.5 \%$ rate of congenital anomalies for insulin aspart among 322 women with type 1 diabetes, 
comparable to a $6.6 \%$ rate for human insulin. ${ }^{23}$ Most studies exploring the use of insulin glargine in pregnant women with diabetes are small, retrospective and without a reference group. A meta-analysis of eight studies on the use of insulin glargine in pregnancy showed a similar rate of congenital anomalies $(8.1 \%)$ compared with the use of neutral protamine Hagedorn (NPH) $(7.7 \%$ ) (OR 0.97, $95 \% \mathrm{CI} 0.47$ to 1.99$).^{25} \mathrm{~A}$ multinational randomised control trial showed that the frequencies of congenital anomaly among insulin detemir or NPH were similar (insulin detemir: $\mathrm{n}=8 / 142,5.6 \%$; $\mathrm{NPH}: \mathrm{n}=8 / 145,5.5 \%) .{ }^{24}$

Our findings confirm and extend these observations. The risk of congenital anomalies was lower in fetuses exposed to insulin analogues, in particular short-acting insulin analogue only, in the first trimester compared with those exposed to human insulin. This decrease was driven by a reduction of risk for congenital heart defects. Studies outside pregnancy have showed that the use of insulin analogues has been associated with either modestly improved glycaemic control or fewer hypoglycaemic episodes. ${ }^{10} 12$ Recent data have emphasised the role of glucose stability in the pathogenesis of fetal malformations, as a single day of poor glycaemic control had potential for a negative impact on organogenesis. ${ }^{26} 27$ It is possible that insulin analogues reduced the risk of congenital anomalies by achieving better glucose stability and consequently reduced glucose-level variation. We might speculate that patients treated with insulin analogues had less frequent very high glucose spikes or hypoglycaemic episodes that might be responsible for impaired fetal development in very early pregnancy. However, our study is lacking information on glucose variability, which may also be a confounding factor. Much remains to be learnt about the biological mechanisms that explain the observed association between insulin analogues and congenital anomalies and whether insulin analogues could reduce the risk of congenital heart defects. The rate of major congenital anomalies was $8.0 \%$ in the reference group-exposure to the human insulin only. This rate is higher compared with the rate of congenital anomalies in the recent UK National Pregnancy and Diabetes Audit: 46.2 for type 1 diabetes and 34.6 for type 2 diabetes per 1000 live births and stillbirths. ${ }^{28}$ This suggests that hyperglycaemia might be more severe, more frequent or possibly due to less adherence to treatment among women with diabetes in the human insulin only group. This may have exacerbated the difference in insulin analogue and human insulin outcomes beyond purely treatment-related effects. Although we do not have a clear explanation for this higher rate, it calls for increased counselling efforts towards diabetic women of childbearing age.

In our data, pregnancies with exposure to insulin analogues had significantly higher rate of spontaneous abortion compared with exposure to human insulin, which has not been previously reported. When we combined the adverse outcomes, including fetal death and congenital anomaly, we did not see increased risks with insulin analogues compared with human insulin. There were two cases with severe congenital heart defects among fetuses exposed to human insulin only and 0 cases of severe congenital heart defects in the insulin analogue only exposed group. These numbers are too small to interpret and formulate any conclusions. It is difficult to say which is worse scenario: the increased risk (if verified) of early-spontaneous abortion following exposure to insulin analogues or the increased risk of septal defect, that often close spontaneously, following exposure to human insulin only. There were no cases with the caudal regression sequence. We would not expect to have a case in our cohort of 1661 fetuses due to its low prevalence ( 1 per 50000 births), ${ }^{29}$ although caudal regression sequence is highly associated with maternal diabetes with OR $>20$ compared with pregnancies without diabetes. ${ }^{6}$

Our study established a large, retrospective cohort of pregnancies with diabetes, with detailed information on treatment of diabetes, HbAlc value and other exposure characteristics. The strength of this study is its use of multiple centres that represent geographically distinct areas where patterns of treatment of diabetes are different. Another strength of the study was the valid information on congenital anomaly gained by linking to the EUROCAT database and by reclassifying the cases with written text descriptions of a congenital anomaly based on EUROCAT subgroup definition. The EUROCAT database includes well-validated, comparable and specific information on congenital anomalies in births as well as terminations of pregnancies. In addition, the associations between some well-known risk factors (such as HbAlc and planned pregnancy) and congenital anomalies in pregnancies with diabetes were consistent with prior reports, supporting the premise that the exposures and outcomes of interest were well captured in our study.

Our results should be interpreted in the context of limitations inherent in its design and local variations. We tried to identify potential confounders of the association between treatment of diabetes and subsequent congenital anomalies, but it remains possible that residual bias is still present because of unmeasured or not perfectly measured or unknown confounders, for example, other as yet unknown differences between groups of insulin use. Our study is a retrospective cohort with information based on medical records and healthcare databases, which were not primarily designed for the current research purposes in most centres. Our data sources have incomplete data on HbAlc and pregnancy planning, which may represent a source of potential residual confounding. Fetuses of mothers with missing values of HbAlc had an increased risk of congenital anomalies/ congenital heart defects in our data. In the sensitivity analysis by including 'missing HbAlc value' in the model as a separate group, the risk estimation did not show a significant difference from the analysis that excluded missing HbAlc. We were not able to adjust for preconception care (eg, screening and treatment of complications of diabetes, folic acid supplementation) which 
is also known to lower the risk of congenital anomaly. In addition, it is possible that the underlying choice of insulin analogue, human insulin or the switch to insulin analogue may confound the risk estimation in the study. Information on the use of an insulin pump, which may have an important impact on the stability of glucose level control, is missing in our study. Pregnant women with renal disease might have a higher risk of congenital anomalies, but information on microvascular complications, particularly diabetic nephropathy is lacking. The cohort data were collected at centres for pregnancies with diabetes and the gestational age at referral to these centres may differ between regions. Therefore, the inclusion of spontaneous abortions may differ. The low rate of spontaneous abortion in our study may be due to the medical records not starting very early in pregnancy; therefore, early spontaneous abortion may not have been captured in our database. Spontaneous abortion was not a primary outcome of the study. Ascertainments of congenital anomalies procedures vary between registries, although we adjusted for region in the analysis. The follow-up period for inclusion of congenital anomalies varies in the EUROCAT registries. As septal defects often are diagnosed after the neonatal period depending on the local protocol, there may be a difference in the inclusion of ASD and VSD. On the other hand, regions with frequent use of echocardiography in the neonatal units may diagnose more septal defects in the neonatal period. ${ }^{30}$ A further limitation of this analysis is the low number of exposed cases, and even though we applied methods appropriate for small cell counts, our ability to control confounding is limited. The absolute numbers of anomalies are small and may be a chance finding or explained by unadjusted confounders. While the biological effect varies according to each type of insulin among short-acting or long-acting insulin analogues, the low numbers of anomalies limited our ability to evaluate the risk in relation to each individual analogue. Because the database did not contain information on lifestyle factors (eg, smoking, obesity, alcohol), we were not able to examine their potential for such confoundings.

In conclusion, our results suggest that first trimester use of insulin analogues does not increase the risk of a congenital anomaly among women with diabetes compared with the use of human insulin. This is the first study that shows a significantly lower risk of congenital heart defects in relation to insulin analogue use, but caution is warranted due to the small numbers of anomalies and the as yet unknown confounders. Our study provides a further piece of evidence on the relative safety of insulin analogues with regards to congenital anomaly, in particular to congenital heart defects. The relative higher proportion of spontaneous abortion among women exposed to insulin analogues observed in our study needs to be investigated in an independent dataset as it was not the primary outcome of our study.
Author affiliations

${ }^{1}$ Pharmacoepidemiology and Pharmacoeconomics, University of Groningen, Groningen, The Netherlands

${ }^{2}$ Division of Reproduction, Poznan University of Medical Sciences, Poznan, Poland

${ }^{3}$ Paediatric Department, Hospital Lillebaelt, Kolding, Denmark

${ }^{4}$ Obstetrician \& Gynaecologist, Singleton Hospital, Swansea, UK

${ }^{5}$ School of Nursing, Ulster University, Northern Ireland, UK

${ }^{6}$ Queen Mary University of London, London, UK

${ }^{7}$ Faculty of Medical Science, University Medical Centre Groningen, Groningen, The Netherlands

${ }^{8}$ Department of Health Information and Research, Ministry of Health, Valletta, Malta ${ }^{9}$ School of Nursing, Swansea University, Swansea, UK

${ }^{10}$ Department of Medical Genetics, Poznan University of Medical Sciences, Poznan, Poland

${ }^{11}$ Provinciaal Instituut voor Hygiene, Antwerp, Belgium

${ }^{12}$ Birth Registry Mainz Model, Children's Hospital, University Medical Center of

Mainz, Mainz, Germany

${ }^{13}$ Ulster University, Northern Ireland, UK

Acknowledgements We thank Dr Thera Links (The Netherlands), Dr Bruce Wolffenbuttel (The Netherlands), Dr Loek de Heide (The Netherlands), Dr Klaas Hoogenberg (The Netherlands), Dr Annette Queißer-Wahrendorf (Germany), Dr Gabi Stolz (Germany), Rhian Thomas (UK), David Tucker (UK), Professor Anna Latos-Bielenska (Poland), Dr Pawel Gutaj (Poland), Anna Jamry-Dziurla (Poland), Zofia Kierznowska (Poland), who contributed to data collection of local cohort of pregnancies with diabetes. We thank Kacie Smith (UK) and James Densem (UK) who contributed to set up database. We thank Anne Vinkel Hansen (Demark) who assisted with data analysis.

Contributors HW: drafting/revising the manuscript for content; study concept or design; analysis or interpretation of data; acquisition of data; statistical analysis; study supervision or coordination. EW-0: drafting/revising the manuscript for content; analysis or interpretation of data; study supervision or coordination; obtaining funding only for meetings attending. EG: reviewed all drafts of the manuscript for content; study concept or design; analysis or interpretation of data; acquisition of data; study supervision or coordination as Steering Group member; obtaining funding; attended all meetings. MM: drafting/revising the manuscript for content; study concept or design; analysis or interpretation of data; acquisition of data. ML: drafting/revising the manuscript for content; analysis of interpretation of data; acquisition of data; study supervision or coordination. JKM: drafting/revising the manuscript for content; analysis or interpretation of data; statistical analysis. MKB: drafting/revising the manuscript for content; analysis or interpretation of data; acquisition of data. MG: drafting/revising the manuscript for content; acquisition of data. HW: drafting/revising the manuscript for content; acquisition of data. SJ: drafting/revising the manuscript for content; study concept or design; analysis or interpretation of data; acquisition of data; study supervision or coordination; obtaining funding. AM-K: acquisition of data. VN and GT: drafting/revising the manuscript for content; acquisition of data. AW: drafting/revising the manuscript for content; study concept or design; analysis or interpretation of data; acquisition of data; statistical analysis; study supervision or coordination. HD: drafting/revising the manuscript for content; study concept or design; analysis of interpretation of data; statistical analysis; study supervision or coordination; obtaining funding. LTWJ-B: drafting/revising the manuscript for content; study concept or design; analysis or interpretation of data; acquisition of data; study supervision or coordination; obtaining funding; attended all meetings of EUROmediCAT.

Funding This study was part of the EUROmediCAT research project (www. euromedicat.eu) which has been supported by the European Commission under the Seventh Framework Programme Grant agreement no 260598.

Competing interests EW-0 is a member of Polish Novo Nordisk advisory board, she gives lectures and leads workshops organised by Eli Lilly and Novo Nordisk in Poland.

Patient consent Not required.

Ethics approval Approval was received from an ethical standards committee in each country.

Provenance and peer review Not commissioned; externally peer reviewed.

Data sharing statement № additional data are available.

Open Access This is an Open Access article distributed in accordance with the Creative Commons Attribution Non Commercial (CC BY-NC 4.0) license, which permits others to distribute, remix, adapt, build upon this work non-commercially, 
and license their derivative works on different terms, provided the original work is properly cited and the use is non-commercial. See: http://creativecommons.org/ licenses/by-nc/4.0/

(C) Article author(s) (or their employer(s) unless otherwise stated in the text of the article) 2018. All rights reserved. No commercial use is permitted unless otherwise expressly granted.

\section{REFERENCES}

1. Jensen DM, Damm P, Moelsted-Pedersen L, et al. Outcomes in type 1 diabetic pregnancies: a nationwide, population-based study. Diabetes Care 2004;27:2819-23.

2. Evers IM, de Valk HW, Visser GH. Risk of complications of pregnancy in women with type 1 diabetes: nationwide prospective study in the Netherlands. BMJ 2004;328:915.

3. Persson M, Norman M, Hanson U. Obstetric and perinatal outcomes in type 1 diabetic pregnancies: A large, population-based study. Diabetes Care 2009;32:2005-9.

4. Macintosh MC, Fleming KM, Bailey JA, et al. Perinatal mortality and congenital anomalies in babies of women with type 1 or type 2 diabetes in England, Wales, and Northern Ireland: population based study. BMJ 2006;333:177.

5. Vinceti M, Malagoli C, Rothman KJ, et al. Risk of birth defects associated with maternal pregestational diabetes. Eur J Epidemiol 2014;29:411-8.

6. Garne E, Loane M, Dolk H, et al. Spectrum of congenital anomalies in pregnancies with pregestational diabetes. Birth Defects Res A Clin Mol Teratol 2012;94:134-40.

7. Reece EA, Homko CJ. Why do diabetic women deliver malformed infants? Clin Obstet Gynecol 2000;43:32-45.

8. Inkster ME, Fahey TP, Donnan PT, et al. Poor glycated haemoglobin control and adverse pregnancy outcomes in type 1 and type 2 diabetes mellitus: systematic review of observational studies. $B M C$ Pregnancy Childbirth 2006;6:30

9. Wahabi HA, Alzeidan RA, Bawazeer GA, et al. Preconception care for diabetic women for improving maternal and fetal outcomes: a systematic review and meta-analysis. BMC Pregnancy Childbirth 2010;10:63

10. Horvath $\mathrm{K}$, Jeitler $\mathrm{K}$, Berghold $\mathrm{A}$, et al. Long-acting insulin analogues versus NPH insulin (human isophane insulin) for type 2 diabetes mellitus. Cochrane Database Syst Rev 2007;(2):CD005613.

11. Hirsch IB. Insulin analogues. N Engl J Med 2005;352:174-83.

12. Siebenhofer A, Plank J, Berghold A, et al. Short acting insulin analogues versus regular human insulin in patients with diabetes mellitus. Cochrane Database Syst Rev 2004 (2):CD003287.

13. de Jong J, Garne E, Wender-Ozegowska E, et al. Insulin analogues in pregnancy and specific congenital anomalies: a literature review. Diabetes Metab Res Rev 2016;32:366-75.
14. Dolk H, Jentink J, Loane $M$, et al. Does lamotrigine use in pregnancy increase orofacial cleft risk relative to other malformations? Neurology 2008;71:714-22.

15. EUROCAT. EUROCAT Guide 1.3 and Reference Documents, Instructions for the Registration and Surveillance of Congenital Anomalies. Northern Ireland, UK: EUROCAT, 2015.

16. Visser $\mathrm{GH}$, Eilers PH, Elferink-Stinkens PM, et al. New Dutch reference curves for birthweight by gestational age. Early Hum Dev 2009;85:737-44.

17. Casson IF, Clarke CA, Howard CV, et al. Outcomes of pregnancy in insulin dependent diabetic women: results of a five year population cohort study. BMJ 1997;315:275-8.

18. Boyd PA, Haeusler M, Barisic I, et al. Paper 1: The EUROCAT network - organization and processes. Birth Defects Res A Clin Mol Teratol 2011;91(Suppl 1):S2-15.

19. Miller JL, de Veciana M, Turan S, et al. First-trimester detection of fetal anomalies in pregestational diabetes using nuchal translucency, ductus venosus Doppler, and maternal glycosylated hemoglobin. Am J Obstet Gynecol 2013;208:385.e1-385.e8.

20. Miller E, Hare JW, Cloherty JP, et al. Elevated maternal hemoglobin A1c in early pregnancy and major congenital anomalies in infants of diabetic mothers. N Engl J Med 1981;304:1331-4.

21. Charlton RA, Klungsøyr K, Neville AJ, et al. Prescribing of Antidiabetic Medicines before, during and after Pregnancy: A Study in Seven European Regions. PLoS One 2016;11:e0155737.

22. Wyatt JW, Frias JL, Hoyme HE, et al. Congenital anomaly rate in offspring of mothers with diabetes treated with insulin lispro during pregnancy. Diabet Med 2005;22:803-7.

23. Hod M, Damm P, Kaaja R, et al. Fetal and perinatal outcomes in type 1 diabetes pregnancy: a randomized study comparing insulin aspart with human insulin in 322 subjects. Am J Obstet Gynecol 2008;198:186.e1-186.e7.

24. Hod M, Mathiesen ER, Jovanovič L, et al. A randomized trial comparing perinatal outcomes using insulin detemir or neutral protamine Hagedorn in type 1 diabetes. J Matern Fetal Neonatal Med 2014;27:7-13.

25. Pollex E, Moretti ME, Koren G, et al. Safety of insulin glargine use in pregnancy: a systematic review and meta-analysis. Ann Pharmacother 2011;45:9-16.

26. Wender-Ozegowska E, Wróblewska K, Zawiejska A, et al. Threshold values of maternal blood glucose in early diabetic pregnancy prediction of fetal malformations. Acta Obstet Gynecol Scand 2005:84:17-25.

27. de Valk HW, Visser GH. Insulin during pregnancy, labour and delivery. Best Pract Res Clin Obstet Gynaecol 2011;25:65-76.

28. NHS UK. National pregnancy in diabetes audit report - 2015. London, UK: NHS UK, 2016.

29. Anonymous. Caudal regression sequence:2016.

30. Garne E, Olsen MS, Johnsen SP, et al. How do we define congenital heart defects for scientific studies? Congenit Heart Dis 2012;7:46-9. 